\title{
A OPERAÇÃO “LEITE COMPENSADO” E AS PERCEPÇÕES DOS CONSUMIDORES DE LEITE NO MUNICÍPIO DE PANAMBI/RS
}

\author{
ANDREATTA, Tanice ${ }^{1}$ \\ COSTA, Nilson Luiz ${ }^{2}$ \\ SANTOS, Izis Freire dos ${ }^{3}$ \\ BINELLO, Lidiane ${ }^{4}$
}

\begin{abstract}
RESUMO: Nesta pesquisa teve-se o objetivo de analisar as percepções dos consumidores de leite do município de Panambi/RS, após as fraudes constatadas no segmento do leite no estado do Rio Grande do Sul. Os dados foram coletados nos meses de maio e junho de 2015, a amostra é composta de 389 observações, estatisticamente significativa, considerando os consumidores de leite no município de Panambi/RS. Para análise dos dados foi utilizado a técnica multivariada de Análise Fatorial Exploratória (AFE). Entre os principais resultados, destacam-se as preocupações dos consumidores em relação à qualidade do leite; o possível retorno a padrões de consumo antigos através da preferência pelo leite não processado, as falhas e ilegalidades ao longo da cadeia produtiva e a preocupação com a saúde. Entre os principais desafios para o segmento, destaca-se a importância de (re)construir a reputação da cadeia produtiva e garantir a qualidade do leite produzido no Rio Grande do Sul.
\end{abstract}

Palavras-chave: Adulteração. Consumidor. Leite

\section{THE OPERATION "MILK COMPENSATED" AND AS PERCEPTIONS OF CONSUMERS OF MILK OF MUNICIPALITY OF PANAMBI / RS}

SUMMARY: The objective of this research was to analyze the perceptions of milk consumers in the municipality of Panambi/RS, after the frauds detected in the milk processing segment in the state of Rio Grande do Sul. The data were collected in May and June of 2015, the sample is composed of 389 observations, statistically significant, considering milk consumers in the municipality of Panambi /RS. The multivariate exploratory factor analysis technique was used to analyze the data. Among the main results, the consumers' concerns about milk quality stand out; the possible return to old patterns of consumption through preference for unprocessed milk, failures and illegalities along the production chain and concern for health. Among the main challenges for the segment, the importance of (re) building the reputation of the production chain and guaranteeing the quality of the milk produced in Rio Grande do Sul stands out.

Keywords: Adulteration. Consumer. Milk

\section{INTRODUÇÃO}

O leite é um produto agropecuário que, além de ser essencial para a saúde humana, representa a geração de emprego e renda ao longo da cadeia produtiva. A atividade leiteira se constitui em "uma atividade básica para grande parte dos agricultores das regiões em que predomina a produção familiar, especialmente aqueles que dispõem de pequenas e médias unidades de produção" (SILVA NETO; BASSO, 2005, p. 59).

\footnotetext{
${ }^{1}$ Professora Associada no Departamento de Ciências Econômicas - Universidade Federal de Santa Maria Programa de Pós Graduação em Agronegócios UFSM - Campus Palmeira das Missões

${ }^{2}$ Professor Adjunto no Departamento de Ciências Econômicas - Universidade Federal de Santa Maria

Programa de Pós Graduação em Agronegócios UFSM - Campus Palmeira das Missões

${ }^{3}$ Economista - Mestranda em Agronegócios - Programa de Pós Graduação em Agronegócios UFSM - Campus

Palmeira das Missões

${ }^{4}$ Economista -Universidade Federal de Santa Maria - Campus Palmeira das Missões
} 
De acordo com Souza e Waquil (2008, p.1), "um em cada três estabelecimentos classificados como agricultura familiar produzem alguma quantidade de leite no Brasil, demonstrando a sua importância para esse segmento dos produtores". Assim, a atividade leiteira é versátil, em termos de diferentes escalas e condições edafoclimáticas e contribui para geração de emprego e renda no meio rural.

Além da tradição na produção de leite, o estado do Rio Grande do Sul possui expressividade na transformação da produção leiteira, uma vez que, a quantidade de leite cru adquirido pelas indústrias processadoras foi de aproximadamente três milhões/litros, no ano de 2016 (INSTITUTO BRASILEIRO DE GEOGRAFIA E ESTATÍSTICA, 2015).

O consumo ideal de leite deveria ser de aproximadamente 210 litros/ano por pessoa, segundo recomendações do Ministério da Saúde; contudo, o consumo do brasileiro no ano de 2015 situou-se ao redor de 174,4 litros/ano (COMPANHIA NACIONAL DE ABASTECIMENTO, 2017; USDA, 2014). Neste contexto, existe espaço para crescimento e desenvolvimento da atividade no mercado interno. Por outro lado, a expansão no mercado externo depende de avanços significativos em critérios de sanidade e qualidade do leite, para ter condições de competir o mercado internacional (VALLIN et al., 2009).

Apesar do estado do Rio Grande do Sul apresentar produção e produtividade expressiva no cenário nacional, a credibilidade do leite produzido e envazado no Estado foi fortemente impactada a partir da descoberta de adulterações do produto. Em maio de 2013, o Ministério Público do Rio Grande do Sul deflagrou uma série de investigações que resultou no desvelamento de um esquema fraudulento envolvendo diversos agentes da Cadeia Produtiva do Leite.

Considera-se fraudado, adulterado ou falsificado o leite que sofrer adição de água; tiver sofrido subtração de qualquer dos seus componentes; exclusive a gordura nos tipos "C" e "magro"; for adicionado de substâncias conservadoras ou de quaisquer elementos estranhos à sua composição; for de um tipo e se apresentar rotulado como de outro de categoria superior; estiver cru e for vendido como pasteurizado; for exposto ao consumo sem as devidas garantias de inviolabilidade (BRASIL, 1952).

De acordo com Egito et al. (2006), adulterações e fraudes no leite resultam em impactos econômicos e riscos à saúde dos consumidores; elas também causam problemas para as indústrias, um exemplo disso é diminuição do rendimento industrial. Entre os principais impactos das fraudes pode-se apontar: "a redução do rendimento, o maior gasto com as operações unitárias industriais, a diminuição do valor nutricional, a alteração da qualidade dos produtos beneficiados e o risco aos consumidores em virtude da presença de determinadas substâncias potencialmente perigosas" (CORTEZ et al., 2010, p.19).

Um estudo conduzido por Brandão et al.(2016), junto a representantes de três cooperativas que atuam na industrialização de leite no estado do RS, no ano de 2016, aponta para impactos significativos na cadeia como um todo, e as consequências foram sentidas nas três cooperativas. Entre os principais efeitos negativos, conforme menciona o entrevistado de uma das cooperativas foi a queda no preço do leite in natura. Já os entrevistados das outras duas cooperativas mencionam que o impacto se deu a medida que eles foram "lesados devido à perda de confiança dos consumidores" (BRANDÃO, et al., 2016, p.12).

Constatação semelhante foi obtida por Roncato, Roncato e Wilwock (2017) a partir de um estudo com representantes de instituições que atuam da atividade leiteira nos municípios de Boa Vista do Buricá, Horizontina e Três de Maio, no Norte do Estado do Rio Grande do Sul. Os autores demonstram que o comportamento oportunista em um dos elos da cadeia do leite causou prejuízos para o produtor, para a indústria e para os consumidores (RONCATO; RONCATO ; VILWOCK, 2017).

Nesta perspectiva, o objetivo neste artigo foi o de analisar as percepções dos consumidores de leite do município de Panambi/RS, após as fraudes no segmento de processamento de leite no estado do Rio

Grande do Sul,investigadas no âmbito da operação "Leite Compensado". 


\section{ASPECTOS TEÓRICOS RELACIONADOS AO CONSUMO DE PRODUTOS AGROALIMENTARES}

A teoria econômica tradicional sugere que entre as variáveis que determinam a demanda, estão as preferências do consumidor, que juntamente com as demais determinam a magnitude da demanda de determinado bem em um tempo específico (PINDYCK; RUBINFELD, 2005). Neste aspecto, as preferências tendem a serem sensíveis à percepção de qualidade e segurança alimentar, quando se trata de um produto destinado à alimentação da família.

De acordo com Kotler (2000), os estudos sobre o comportamento do consumidor buscam identificar como as pessoas, grupos e organizações selecionam, compram, usam e descartam produtos, serviços, ideias ou experiências para satisfazer suas necessidades e seus desejos.

Ainda que a teoria econômica tradicional considere o preço como o fator chave na tomada de decisão de compra dos consumidores, quando se trata a produtos alimentícios, existem outros fatores tendem a influenciar de forma significativa nas decisões. Em linhas gerais, o consumidor está cada vez mais criterioso quanto aos produtos que vai ingerir e a preocupação com a saúde tem se tornado cada vez mais evidente, sobretudo em momentos em que são expostos riscos à saúde.

Para Neves et al.(2011, p.74), os fatores que mais implicam na hora de decidir pela compra de alimentos, por ordem de importância, são "frescor, nutrição, sabor, segurança, preço e conveniência". Neste aspecto, a segurança alimentar, relacionada à qualidade nutricional dos alimentos, é uma variável que os consumidores consideram no momento da decisão de compra. Neste contexto, a preferência na hora da compra está sujeita a avaliações como preço, aparência, praticidade e qualidade, sempre levando em conta questões como benefícios e malefícios a saúde, bem como o comportamento ético envolvido no processo de produção, até o momento em que é consumido o determinado produto.

De acordo com Santos et al. (2013), o que torna um produto confiável ou não confiável para o consumidor é a presença de propriedades específicas. No caso do leite, estas especificidades estão associadas ao processo de produção e podem não ser visíveis ou identificados a olho nu. Em função disto, ações oportunistas podem ocorrer sem que o consumidor perceba.

Dada a esta situação, os conceitos de rastreabilidade e a confiança tornam-se importantes e podem reduzir a percepção de insegurança ou falta de confiança em relação ao consumo de alimentos produzidos em larga escala. A criação de vínculos entre a produção e o consumo é importante, e, de um modo geral, o Estado é o responsável em regulamentar essa relação. A caracterização da soberania alimentar, de acordo com a FAO (2014, p. 21), "deve ter vistas ao maior controle da inflação e da volatilidade dos preços dos alimentos, e o acesso a alimentos saudáveis e inócuos." Portanto, é um direito de todo cidadão ter acesso a alimentos a preços acessíveis, seguros e saudáveis.

\section{PROCEDIMENTOS METODOLÓGICOS}

Diante deste cenário, procurou-se, em maior ou menor grau, avaliar as consequências das adulterações, a partir da percepção dos consumidores de leite do Rio Grande do Sul, mais especificamente no município de Panambi, um município, 38.058 habitantes (IBGE, 2014), localizado na região Noroeste do Estado do Rio Grande do Sul.

De acordo com estatística disponível no IPEAData (2015), a população economicamente ativa no município considerado na pesquisa é de aproximadamente de 17.903 pessoas. Com base nessa população, calculou-se o tamanho da amostra, ao nível de confiança de $95 \%$ de confiança. O cálculo amostral revelou a necessidade de realização de 376 questionários com consumidores de leite, no entanto, o número de 
pessoas que efetivamente responderam o questionário foi de 389. Os respondentes foram escolhidos aleatoriamente. A aplicação dos questionários ocorreu nos meses de abril e maio de 2015.

O questionário continha 56 questões: oito delas foram caracterizadas como abertas e as outras 48 caracterizadas como fechadas, organizadas com base na escala de Likert. $O$ primeiro bloco continha questões relacionadas às características do perfil dos respondentes como: gênero, ano de nascimento, escolaridade, renda mensal familiar, estado civil, número de pessoas por residência, e quais eram as quatro marcas de leite que lembravam primeiramente. Na sequência, foram abordadas questões como: preferências por tipos específicos de produtos, local de compra, gostos e motivos de consumo, entre outros. Por último foram abordadas questões referentes aos processos de adulteração do leite e o reflexo nas decisões dos consumidores.

Além da análise de frequência foi realizada uma análise fatorial exploratória. De acordo com Fávero et al.(2009), a análise fatorial constitui-se em uma técnica de interdependência que tem por objetivo sintetizar as relações observadas entre um conjunto de variáveis inter-relacionadas. Ela permite identificar fatores comuns, assim como simplificar ou reduzir um grande número de dados, por intermédio da determinação das dimensões latentes, também conhecidas por fatores, possibilitando ao pesquisador a criação de indicadores inicialmente não observáveis compostos do agrupamento de variáveis para o tratamento de dados.

Neste contexto, os fatores dela resultantes permitem compreender uma realidade, analisar comportamentos e identificar tendências e informações derivadas de variáveis métricas. O número de fatores foi determinado pelo critério da raiz latente. O método de rotação ortogonal utilizado foi o Varimax. Os testes utilizados para aferir a adequação da amostra ao modelo de análise fatorial foram o Kayser-Meyer-Olkin e o teste de esfericidade de Bartlett.

\section{PERCEPÇÕES DOS CONSUMIDORES DO MUNICÍPIO DE PANAMBI (RS) FRENTE AOS CASOS DE ADULTERAÇÃO DE LEITE NO RS}

As notícias quanto à adulteração do leite foram amplamente divulgadas através dos meios de comunicação no Rio Grande do Sul, o que levou os consumidores, em maior ou menor grau, a preocuparem-se com a qualidade do produto que estavam consumindo.

Nesta perspectiva, considerando o perfil dos indivíduos que compõem a amostra, 59\% deles eram do sexo feminino e $41 \%$ do sexo masculino. A média de idade dos entrevistados foi de 36 anos. Quanto à escolaridade, 9,25\% dos indivíduos possuía ensino fundamental incompleto, 5,66\% possuía ensino fundamental completo, $11,31 \%$ possuía ensino médio incompleto, $23,14 \%$ possuía ensino médio completo, $25,45 \%$ possuía ensino superior incompleto, $17,48 \%$ possuía ensino superior completo e 7,71\% possuía Pós-Graduação concluída ou em andamento.

Em relação à renda mensal média familiar dos respondentes destaca-se que: 2,31\% deles possuía renda familiar média de até um salário mínimo, em 32,65\% da amostra a renda familiar variava entre 1,1 e 3 salário mínimos, em 33,68\% a renda variava entre 3,1 a 5 salários mínimos, em 15,94\% a renda observada variava entre 5,1 e 7 salários mínimos e os demais possuíam renda acima de sete salários mínimos. No que se refere ao número de pessoas que residiam no mesmo domicílio, averiguou-se que em 29,56\% residiam em até duas pessoas; em 33,93\% residiam três pessoas, em 29,31\% residiam quatro pessoas e os demais $(7,20)$ de 5 ou mais pessoas.

A partir da sistematização das respostas dos entrevistados, percebeu-se que em torno de $50 \%$ dos entrevistados consumia leite advindo de empresas envolvidas com as adulterações de leite (Tabela 1). O nível significativo do consumo tende a estar associado aos preços praticados, assim como pelo fato de 
que algumas empresas eram das Regiões Norte e Noroeste do estado Rio Grande do Sul.

Questionados sobre a quantidade consumida logo após as investigações do Ministério Público e da divulgação na imprensa regional e nacional, $50 \%$ dos respondentes mencionou que reduziu o consumo de leite (Tabela 1). Uma das consequências observadas depois dos casos de adulteração pelas empresas lácteas, conforme apontou o IBGE (2015), foi a redução do comércio de leite.

Em relação aos efeitos causados à saúde humana, decorrente de adições de substâncias químicas no leite, pode-se verificar que grande parte dos consumidores estava temerosa quanto à qualidade do produto, e creem que o leite possui substâncias nocivas à saúde humana. Os dados revelam que, dos 389 entrevistados, 236 deles que corresponde a 60,66\%, concordou que o leite adulterado possui substâncias prejudiciais à saúde, mostrando-se um resultado expressivo.

Após as adulterações de leite, considerando os entrevistados do município de Panambi/RS, pode se constatar dois aspectos chaves, envolvendo a comercialização de leite. O primeiro diz respeito à troca de marcas, ou seja, 51,28\% dos respondentes (tabela 1) trocaram de marca, em decorrência das adulterações. O segundo, é que os consumidores $(59,49 \%)$ optaram por pagar mais caro por marcas que não estavam sendo investigadas na Operação "Leite Compensado". Mesmo assim, um percentual significativo $(52,54 \%)$ dos consumidores, não se sentia seguros em consumir leite industrializado.

Tabela 1. Frequência (em \%) das variáveis representativas que fazem parte da composição da matriz fatorial

(Continua)

\begin{tabular}{|c|c|c|c|c|}
\hline Variáveis & $\begin{array}{c}\text { Discordo } \\
\text { parcialmente ou } \\
\text { totalmente }\end{array}$ & $\begin{array}{c}\text { Não concordo } \\
\text { e nem } \\
\text { discordo }\end{array}$ & $\begin{array}{c}\text { Concordo } \\
\text { parcialmente ou } \\
\text { totalmente }\end{array}$ & $\begin{array}{c}\text { Não } \\
\text { sabe/Não } \\
\text { respondeu }\end{array}$ \\
\hline Consumia leite de marcas suspeitas & 38,30 & 8,23 & 51,15 & 2,31 \\
\hline $\begin{array}{l}\text { Diminuiu o consumo após as } \\
\text { adulterações de leite }\end{array}$ & 35,48 & 13,11 & 50,13 & 1,29 \\
\hline Leite adulterado prejudica a saúde & 25,96 & 11,83 & 61,96 & 0,25 \\
\hline $\begin{array}{l}\text { Troquei de marca após saber das } \\
\text { adulterações }\end{array}$ & 36,26 & 11,05 & 51,15 & 1,54 \\
\hline $\begin{array}{l}\text { Pago mais, mas compro marcas não } \\
\text { envolvidas com adulterações }\end{array}$ & 25,71 & 13,37 & 59,39 & 1,53 \\
\hline $\begin{array}{l}\text { Considero importante a textura do } \\
\text { leite }\end{array}$ & 24,28 & 14,91 & 59,38 & 1,03 \\
\hline $\begin{array}{l}\text { Considero importante o cheiro do } \\
\text { leite }\end{array}$ & 23,39 & 13,11 & 61,70 & 1,80 \\
\hline $\begin{array}{l}\text { Considero importante o sabor do } \\
\text { leite }\end{array}$ & 21,09 & 11,31 & 65.30 & 2,30 \\
\hline $\begin{array}{l}\text { o Leite não processado é mais } \\
\text { saudável e confiável }\end{array}$ & 28,54 & 14,91 & 54,76 & 1,80 \\
\hline Prefiro comprar do produtor rural & 59,90 & 16,20 & 22,36 & 1,54 \\
\hline $\begin{array}{l}\text { o Preço é um fator importante em } \\
\text { minha decisão de compra }\end{array}$ & 23,38 & 17,99 & 57,84 & 0,77 \\
\hline $\begin{array}{l}\text { Se a renda aumentar vou aumentar } \\
\text { o consumo }\end{array}$ & 54,87 & 17,69 & 26,67 & 0,77 \\
\hline $\begin{array}{l}\text { Se o preço aumentar, vou reduzir o } \\
\text { consumo }\end{array}$ & 46,13 & 13,40 & 39,95 & 0,52 \\
\hline $\begin{array}{l}\text { A culpa das adulterações é da } \\
\text { fiscalização }\end{array}$ & 8,23 & 11,57 & 78,40 & 1,80 \\
\hline
\end{tabular}


Tabela 1. Frequência (em \%) das variáveis representativas que fazem parte da composição da matriz fatorial

(Conclusão)

\begin{tabular}{|c|c|c|c|c|}
\hline Variáveis & $\begin{array}{c}\text { Discordo } \\
\text { parcialmente ou } \\
\text { totalmente } \\
\end{array}$ & $\begin{array}{c}\text { Não concordo } \\
\text { e nem } \\
\text { discordo } \\
\end{array}$ & $\begin{array}{c}\text { Concordo } \\
\text { parcialmente ou } \\
\text { totalmente } \\
\end{array}$ & $\begin{array}{c}\text { Não } \\
\text { sabe/Não } \\
\text { respondeu } \\
\end{array}$ \\
\hline $\begin{array}{l}\text { A culpa das adulterações é das } \\
\text { processadoras (laticínios) }\end{array}$ & 14,64 & 18,77 & 65,05 & 1,54 \\
\hline $\begin{array}{l}\text { A culpa das adulterações é dos } \\
\text { intermediários }\end{array}$ & 26,33 & 17,74 & 53,73 & 1,80 \\
\hline $\begin{array}{l}\text { A culpa das adulterações é dos } \\
\text { produtores rurais }\end{array}$ & 59,65 & 14,91 & 24,42 & 1,01 \\
\hline $\begin{array}{l}\text { Após saber das adulterações passei } \\
\text { a comprar diretamente do produtor } \\
\text { rural }\end{array}$ & 48,85 & 15,17 & 34,44 & 1,54 \\
\hline
\end{tabular}

Fonte: Elaboração dos autores, com base nos dados da pesquisa de campo (2015)

Outro aspecto relevante identificado na tabela 1, é que aproximadamente $55 \%$ dos consumidores entrevistados acredita que frente ao comportamento oportunista de algumas empresas, o consumo de leite cru é mais saudável. Isso remete à discussão em torno dos riscos envolvidos no leite não processado, sobretudo quando a procedência do mesmo é desconhecida.

De um modo geral, a Operação Leite Compensado suscitou uma discussão em torno do comportamento oportunista dos agentes envolvidos na atividade, e como ele pode impactar negativamente em toda a cadeia. Neste contexto, de acordo com a tabela 1, os entrevistados acreditam que culpa é dos produtores $(24,62 \%$ dos respondentes); dos intermediários, (53,85\% dos respondentes); das empresas processadoras (65,13\% dos respondentes). Além disso, na visão de 78,46\% dos consumidores, a culpa das adulterações é da fiscalização deficiente por parte das autoridades sanitárias que não atuam de maneira efetiva em todos os elos da cadeia.

No que se refere ao tratamento estatístico, a amostra mostrou-se adequada para o tratamento quantitativo através da Análise Fatorial Exploratória (AFE), uma vez que o teste Kaiser-Meyer-Olkin situou-se no patamar de 0,699 e o Teste de Esfericidade de Bartlett foi estatisticamente significativo ao nível de $1 \%$ de probabilidade.

Considerando que a determinante da Matriz de Correlações foi diferente de zero, existem condições para a extração dos fatores e cálculo da variância explicada. A variância explicada dos dados foi de $62,66 \%$ e identificou-se seis fatores, que explicam o comportamento e as preocupações dos consumidores, conforme é possível observar na Tabela 2.

Cabe destacar que as comunalidades $\left(h^{2}\right)$, que representam a quantidade de variância que uma variável compartilha com as demais da análise, apresentaram um nível significativo de explicação, pois a grande maioria delas situou-se em patamar superior a 0,5, parâmetro indicado como aceitável em Fávero et al.(2009).

O primeiro fator agregou as variáveis sensoriais, em especial, "textura cheiro e sabor"; explicou $13,61 \%$ da variabilidade dos dados e por isso reflete a atenção dos consumidores com aspectos relacionados à qualidade do produto (Tabela 2). Quando se considera os estudos no campo da alimentação, a análise sensorial figura entre os principais fatores a serem analisados para avaliar o grau de aceitação de um produto alimentício por parte do consumidor. Neste contexto, de acordo com a Associação Brasileira de Normas Técnicas (ABNT, 1993), a análise sensorial se refere às características dos alimentos e dos materiais e, em geral, elas são percebidas pelos sentidos da visão, olfato, gosto, tato e 
audição. Para Loures et al. (2010) a análise sensorial de produtos é fundamental para identificar as variáveis determinantes nas escolhas dos consumidores.

Tabela 2. Matriz de Cargas Fatoriais $(\alpha)$ e comunalidades $\left(\mathrm{h}^{2}\right)$ após a rotação pelo método Varimax

\begin{tabular}{|c|c|c|c|c|c|c|c|}
\hline \multirow{2}{*}{ Variáveis } & \multicolumn{6}{|c|}{ Fatores } & \multirow{2}{*}{$\mathbf{h}^{2}$} \\
\hline & $\mathbf{1}$ & 2 & 3 & 4 & 5 & 6 & \\
\hline Considero importante a textura do leite & $\mathbf{0 , 8 7 7}$ & 0,104 & 0,115 & 0,025 & 0,005 & 0,004 & 0,794 \\
\hline Considero importante o cheiro do leite & $\mathbf{0 , 8 6 0}$ & 0,139 & 0,113 & 0,039 & $-0,055$ & $-0,011$ & 0,776 \\
\hline Considero importante o sabor do leite & 0,849 & $-0,017$ & $-0,011$ & 0,061 & 0,020 & 0,116 & $\mathbf{0 , 7 3 8}$ \\
\hline $\begin{array}{l}\text { Troquei de marca após saber das } \\
\text { adulterações }\end{array}$ & 0,099 & 0,866 & 0,056 & 0,095 & 0,022 & 0,095 & $\mathbf{0 , 7 8 1}$ \\
\hline Consumia leite de marcas suspeitas & $-0,077$ & 0,756 & 0,112 & 0,201 & 0,100 & 0,045 & 0,643 \\
\hline $\begin{array}{l}\text { Pago mais, mas compro marcas não } \\
\text { envolvidas com adulterações }\end{array}$ & 0,269 & 0,706 & 0,072 & $-0,054$ & $-0,034$ & 0,124 & 0,596 \\
\hline $\begin{array}{l}\text { Após saber das adulterações passei a comprar } \\
\text { diretamente do produtor rural }\end{array}$ & $-0,011$ & 0,126 & 0,869 & $-0,019$ & 0,054 & 0,121 & $\mathbf{0 , 7 9 0}$ \\
\hline Prefiro comprar do produtor rural & 0,079 & $-0,016$ & 0,688 & 0,424 & $-0,038$ & 0,011 & 0,661 \\
\hline O Leite cru é mais saudável e confiável & 0,246 & 0,121 & 0,604 & 0,047 & 0,020 & 0,212 & $\mathbf{0 , 4 8 7}$ \\
\hline Se o preço aumentar, vou reduzir o consumo & $-0,030$ & 0,124 & 0,050 & $\mathbf{0 , 8 1 3}$ & 0,036 & 0,117 & 0,695 \\
\hline $\begin{array}{l}\text { O Preço é um fator importante em minha } \\
\text { decisão de compra }\end{array}$ & 0,193 & $-0,005$ & 0,025 & 0,691 & $-0,096$ & 0,024 & $\mathbf{0 , 5 2 6}$ \\
\hline $\begin{array}{l}\text { Se a renda aumentar vou aumentar o } \\
\text { consumo }\end{array}$ & $-0,092$ & 0,250 & 0,323 & $\mathbf{0 , 5 0 2}$ & 0,006 & $-0,051$ & $\mathbf{0 , 4 3 0}$ \\
\hline A culpa das adulterações é do intermediários & 0,020 & $-0,006$ & $-0,191$ & $-0,014$ & $\mathbf{0 , 7 8 5}$ & 0,045 & 0,656 \\
\hline $\begin{array}{l}\text { A culpa das adulterações é dos produtores } \\
\text { rurais }\end{array}$ & $-0,081$ & 0,044 & 0,193 & $-0,018$ & 0,684 & $-0,239$ & $\mathbf{0 , 5 7 1}$ \\
\hline $\begin{array}{l}\text { A culpa das adulterações é das processadoras } \\
\text { (laticínios) }\end{array}$ & 0,029 & 0,008 & 0,109 & $-0,093$ & $\mathbf{0 , 5 7 7}$ & 0,499 & 0,604 \\
\hline Leite adulterado prejudica a saúde & 0,070 & $-0,010$ & 0,106 & 0,008 & $-0,141$ & 0,647 & 0,455 \\
\hline A culpa das adulterações é da fiscalização & 0,062 & 0,174 & 0,102 & 0,044 & 0,391 & $\mathbf{0 , 5 9 6}$ & $\mathbf{0 , 5 5 4}$ \\
\hline $\begin{array}{l}\text { Diminui o consumo após saber das } \\
\text { adulterações }\end{array}$ & $-0,040$ & 0,382 & 0,088 & 0,188 & $-0,097$ & 0,566 & $\mathbf{0 , 5 2 0}$ \\
\hline Soma de quadrados do autovalor & 2,449 & 2,138 & 1,863 & 1,679 & 1,631 & 1,519 & \\
\hline Percentual do Traço & 13,61 & 11,88 & 10,35 & 9,33 & 9,06 & 8,44 & \\
\hline
\end{tabular}

Fonte: Elaboração dos autores, com base nos dados da pesquisa de campo (2015)

O segundo fator (11,88\% da variância explicada) agregou as variáveis "consumia leite de marcas suspeitas; troquei de marca após saber das adulterações; pago mais caro, mas não compro marcas envolvidas com adulterações". Este fator demonstra a deterioração da confiança dos consumidores em relação às marcas que comercializavam leite adulterado e ainda, representa um vetor de mudança, que se direciona à busca por alternativas de consumo mais confiáveis. De acordo com Grunert (2005), a segurança dos alimentos pode ser abordada a partir de duas perspectivas: A primeira, a partir de aspectos objetivos, diz respeito a um conceito baseado a avaliação de risco por cientista e especialistas. A segunda, 
a partir de aspectos subjetivos, que reúne aqueles aspectos relacionados à percepção dos consumidores em relação à segurança dos alimentos. Neste contexto, a medida que o consumidor percebe, seja por meio de aspectos subjetivos e objetivos uma insegurança em relação aos alimentos, a reação imediata é buscar produtos alternativos, ainda que isso implique, em maior dispêndio econômico.

O terceiro fator explicou $10,352 \%$ da variabilidade dos dados e agregou as variáveis que representam um movimento do consumidor no sentido de adquirir o leite diretamente do produtor rural, por acreditar que este é mais saudável. Este fator demonstra a tendência, por parte dos consumidores, de retorno aos padrões de consumo antigos, de leite não processado, direto do produtor. De um modo geral, em momentos de crise relacionada a um produto alimentício, o consumidor tende a se voltar para alternativas, que na sua percepção, lhe proporcione uma menor desconfiança do produto consumido.

Neste contexto, ao considerar o caso dos consumidores de leite do município de Panambi/RS, especificamente, as fraudes do leite, além de causar a "quebra de confiança" ao longo de toda a cadeia, também tem proporcionado o retorno do consumo de leite informal. No entanto, essas escolhas também tendem a carregar um grau de incerteza quanto à qualidade. Pelas suas características nutricionais, bem como das questões relacionados ao manejo, o leite é um produto suscetível ao ataque de um número considerável de microrganismos do meio ambiente, do próprio animal, do homem e dos utensílios utilizados na ordenha (FRANCO et al.,2000).

O quarto fator, com variância explicada de 9,326\%, agregou as variáveis relacionadas ao preço e renda e permitiu identificar que os consumidores são pouco sensíveis a variações na renda, mas um pouco mais sensíveis à variações de preços (tabela 1). De um modo geral, produtos que compõem a alimentação básica, salvo algumas exceções, são considerados inelásticos em relação ao preço e a renda dos consumidores (PINDYCK; RUBINFELD, 2005). No entanto, neste caso em específico, as adulterações em determinadas marcas elevaram significativamente o preço de marcas não envolvidas nas fraudes do leite, o que contribui para explicar porque aproximadamente $30 \%$ dos consumidores se mostraram sensíveis a uma variação nos preços.

O quinto fator representou $9,1 \%$ da variabilidade dos dados e identifica claramente que os consumidores responsabilizam os produtores, os intermediários (transportadores) e as processadoras de leite (laticínios) pelas adulterações. Em linhas gerais, quanto maior o número de agentes atuando em uma determinada cadeia produtiva, como a do leite, por exemplo, maior é a margem para comportamento oportunista dos agentes. De acordo Williamson (1985, p. 47) o oportunismo pode ser caracterizado como "a busca do interesse próprio com malícia, decorre da presença de assimetrias de informação, dando origem a problemas de risco moral e seleção adversa". Neste contexto, o oportunismo, tanto ex-ante e expost, à medida que implica na manipulação ou ocultamento de intenções e/ou informações, tendem a auferir lucros a um determinado agente e/ou grupo de agente, mas por outro, tende a gerar conflitos no âmbito das relações contratuais que regem as transações entre os agentes econômicos nos mercados.

No sexto e último fator ( $8,4 \%$ da variância explicada), agregaram-se as variáveis que destacam a preocupação dos consumidores com a saúde, a redução do consumo após a divulgação das adulterações e a responsabilização do sistema de vigilância sanitária, fatos que compõem um vetor que explica a redução da demanda. Em linhas gerais, a busca por um alto padrão de qualidade nos sistemas agroalimentares tem sido cada vez mais valorizados nos mercados nacionais e internacionais, e se constitui como um fator fundamental na competitividade da indústria de laticínios. Neste sentido, a sensibilidade dos consumidores frente a problemas com a sanidade e a qualidade dos alimentos tem sido casa vez mais elevada, o que impacta de forma evidente em todos os elos da cadeia produtiva. As fraudes iniciadas em 2013 e que culminaram em várias etapas de "Operação Leite Compensado" representam um prejuízo de difícil dimensionamento em todos os elos da cadeia, ocasionados, sobretudo, pela perda de 
confiança dos consumidores. De acordo com Roncato, Roncato e Vilwock (2017, p. 14-15) "Nessa situação não é possível dimensionar com exatidão as consequências negativas para os diferentes elos do setor, mas o fato é que o impacto no médio e longo prazo poderá ser sentido nas escolhas dos consumidores".

Em uma perspectiva mais ampla, a análise permite inferir que a reputação da cadeia produtiva do leite está comprometida, especialmente no município de Panambi/RS e que soluções duradouras para a crise que se abateu no setor devem estar condicionadas à gestão e governança de cadeias produtivas e a reconstrução da imagem deste produto.

\section{CONSIDERAÇÕES FINAIS}

Neste artigo o objetivo foi o de analisar as percepções dos consumidores de leite do município de Panambi/RS, após as fraudes constatadas no segmento na cadeia produtiva do leite no estado do Rio Grande do Sul, e investigadas no âmbito da "Operação Leite Compensado".

Neste contexto, a confiança é um elemento importante nas decisões de consumo. À medida que a reputação de um produto é colocada em xeque, neste caso o leite, ainda que temporariamente, houve uma disposição por parte dos consumidores, de reduzir o consumo, de substituição de marcas, de consumir leite não processado sem inspeção sanitária, além de sentimento generalizado de insegurança acerca do leite produzido no Rio Grande do Sul.

Em uma perspectiva mais ampla, as adulterações de leite sinalizam as dificuldades de regulação e fiscalização do sistema de vigilância sanitária e às organizações que participam da cadeia produtiva do leite no Rio Grande do Sul. Por outro lado, as organizações que conseguirem garantir a oferta de um produto de qualidade e livre da desconfiança que paira no setor, tenderão a aumentar os lucros e a participação neste mercado.

Em linhas gerais, um algum evento em um elo da cadeia repercute, em maior ou menor escala, em todos os elos. Neste sentido, em decorrência da importância produtiva, econômica e social, se evidencia a necessidade de re (constituir) a reputação da cadeia produtiva do leite do Rio Grande do Sul.

\section{REFERÊNCIAS}

ASSOCIAÇÃO BRASILEIRA DE NORMAS TÉCNICAS - ABNT. Análise sensorial dos alimentos e bebidas: terminologia. 1993.

BRANDÃO, J. B. Escândalos no processamento de leite: consequências positivas ou negativas para as cooperativas do Rio Grande do Sul? Congresso da Sociedade Brasileira de Economia, Sociologia e Administração Rural (55). Anais...Universidade Federal de Alagoas. Alagoas. Disponível em: <http://icongresso.itarget.com.br/tra/arquivos/ser.6/1/6311.pdf $>$. Acesso em: fev. 2016.

BRASIL . REGULAMENTO DA INSPEÇÃO INDUSTRIAL E SANITÁRIA DE PRODUTOS DE ORIGEM ANIMAL, 1952. Disponível em: < http://www.planalto.gov.br/ccivil_03/decreto/19501969/d30691.htm >. Acesso em: jun. 2015.

COMPANHIA NACIONAL DE ABASTECIMENTO. Leite e derivados. Conjuntura mensal especial. Disponível em:

<http://www.conab.gov.br/OlalaCMS/uploads/arquivos/17_05_15_14_13_38_leite_abril_2017.pdf $>$. Acesso em: out. 2017. 
CORTEZ M.A.S. et al. Características físico-químicas e análise sensorial do leite pasteurizado adicionado de água, soro de queijo, soro fisiológico e soro glicosado. Rev Inst Latic Cândido Tostes. v.65, n.376, p.18-25, 2010.

EGITO A. S. et. al. Método eletroforético rápido para detecção da adulteração do leite caprino com leite bovino. Arq Bras Med Vet Zootec. v.58, n.5, p.932-939, 2006. Disponível em:

<http://dx.doi.org/10.1590/S0102-09352006000500032>.. Doi: 10.1590/S0102-09352006000500032.

Acesso em: ago 2015.

FAO BRASIL, Organização das Nações Unidas para Alimentação e Agricultura O Estado da Segurança Alimentar e Nutricional no Brasil Um retrato multidimensional Relatório 2014. Disponível em: $\langle$ http://www.fao.org.br/download/SOFI p.pdf $>$. Acesso em: 04 jul. 2015.

FÁVERO, L. P.et al. Análise de dados - modelagem multivariada para tomada de decisões. São Paulo: Campus, 2009.

FRANCO, R.M. et al. Avaliação da qualidade higiênico-sanitária de leite e derivados. Revista Higiene Alimentar, v.14, n.68, p.70-77, 2000.

GRUNERT, K.G. Food quality and safety: consumer perception and demand. European Review of Agricultural Economics, Amsterdam, v.32, n.3. p.369-391, july-sept. 2005. Disponível em: <https://doi.org/10.1093/eurrag/jbi011>. Doi: 10.1093/eurrag/jbi011. Acesso em: ago. 2016.

INSTITUTO BRASILEIRO DE GEOGRAFIA E ESTATÍSTICA- IBGE. IBGE Cidades, 2014. Disponível em: < https://cidades.ibge.gov.br/brasil/rs/panambi/panorama >. Acesso em: 01 fev 2015.

\section{INSTITUTO BRASILEIRO DE GEOGRAFIA E ESTATÍSTICA-IBGE. Produção da pecuária} municipal 2015. Disponível em: <

https://ww2.ibge.gov.br/home/estatistica/economia/ppm/2015/default_sidra.shtm > . Acesso em: fev. 2017.

IPEADATA, I. P. E. A. Dados macroeconômicos e regionais. 2015. Disponível em <http://www. ipeadata. gov. br>. Acesso em: 25 abr. 2015.

KOTLER, P. Administração de Marketing: análise, planejamento, implementação e controle. Edição Milenium. São Paulo: Prentice Hall, 2000.

LOURES, M. M. R. et al. Ranking descriptive analysis in the sensory characterization of strawberry flavored diet yogurt enriched with whey protein concentrate. Semina: Ciências Agrárias, Londrina, v. 31, n. 3, p. 661-668, 2010. Disponível em: <http://dx.doi.org/10.5433/1679-0359.2010v31n3p661> Acesso em: ago 2017.

NEVES, F. M.; CASTRO, L.T. et al. Marketing e Estratégia em Agronegócio e Alimentos. São Paulo: Atlas, 2011.

PINDYCK, R. S; RUBINFELD, D. L. Microeconomia. 6. ed. São Paulo: Pearson Prentice Hall, 2005.

RONCATO, P. E. S.; RONCATO, M. A.; VILWOCK , A.P.S. As Fraudes na Cadeia Produtiva do Leite Um Estudo de Caso na Região Fronteira Noroeste do Rio Grande do Sul Sob a Luz da Nova Economia Institucional. Desenvolvimento em Questão. Editora Unijuí, ano 15, n. 38, jan./mar, 2017. Disponível em: <http://dx.doi.org/10.21527/2237-6453.2017.38.295-318.> Doi: 10.21527/2237-6453.2017.38.295318. Acesso em: jun. 2017.

SANTOS et al. Adequação de restaurantes comerciais às boas práticas, São Paulo, v.24, n.190, p.4449, nov./dez. 2013. 
SILVA NETO, B; BASSO, D. A produção de leite como estratégia de desenvolvimento para o Rio Grande do Sul. Desenvolvimento em questão. Ijuí: Ed. Unijuí, ano 3, n. 5. p. 53-72, jan./jun. 2005. Disponível em: < http://dx.doi.org/10.21527/2237-6453.2005.5.53-72>. doi: 10.21527/22376453.2005.5.53-72. Acesso em: ago 2016.

SOUZA. R; WAQUIL, P. A viabilidade da agricultura familiar produtora de leite: o caso do sistema Coorlac (RS). 47 Congresso da Sociedade Brasileira de Economia, Administração e Sociologia Rural. Congresso da Sober, 47 . Anais[...] 2008. Disponível em <http://ageconsearch.umn.edu/record/112734/files/37.pdf > .Acesso em 18 mai.2016.

USDA. Foreign Agricultural Service. 2014. Disponível em: <

https://apps.fas.usda.gov/psdonline/app/index.html\#/app/home > . Acesso em: ago 2016.

VALLIN, V. M. et al. Melhorias da qualidade do leite a partir da implantação de boas práticas de higiene na ordenha em 19 municípios da região central do Paraná. Semina: Ciências Agrárias, Londrina, v. 30, n. 1, p. 181-188, 2009. Disponível em: < http://dx.doi.org/10.5433/1679-0359.2009v30n1p181 >. Doi: 10.5433/1679-0359.2009v30n1p181. Acesso em: jul. 2016.

WILLIAMSON, O. E. The economic institutions of capitalism: firms, markets, relational contracting. New York: The Free Press, 449p. 1985. 